\title{
Hang Kim, My Mathematical Comrade
}

\author{
F.W. Roush
}

Published online: 6 March 2013

(C) Springer Science+Business Media Dordrecht 2013

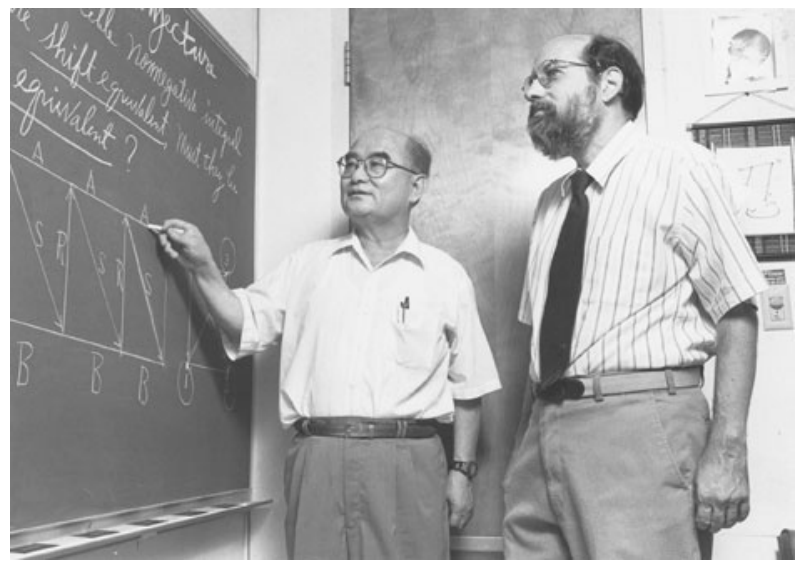

Ki Hang Kim and Fred Roush (1996)

Dr. Kim obtained his Ph.D. at George Washington University. His specialty became Boolean matrix theory and, in search of the leading experts in the field, he went to M.I.T. to study under Gian-Carlo Rota and later under John Rhodes at Berkeley.

Dr. Kim taught at several institutions in the United States and also in Portugal and India. He loved to travel and attend international conferences in his younger days. Hungary and China were particular favorites of his as places to which to travel to conferences. He made friends wherever he went. He was a good collaborator with other mathematicians and 
through his collaborators both of us received an Erdős number of 2. After he had joined the faculty of Alabama State University, I was introduced to him by another member of the mathematics faculty, John Ivery, who thought we might be interested in working together. I then joined the faculty under a grant Dr. Kim had received to set up a computation laboratory. Both of us, I think, were more productive as a result of our thirty-year collaboration; Dr. Kim had published considerably more than I had when we began.

Dr. Kim had a gift for explaining higher mathematics in a simple way in the classroom. Alabama State University has a Masters program in mathematics, and over 25 Masters students wrote their theses under him. One of them, Anthony Hudson, told me that Dr. Kim was one of the best teachers he had ever known.

Dr. Kim sometimes said that mathematics was his avocation as well as his vocation, and often worked 7 days a week. Nonetheless he was active in his community, for instance in the Korean-American Methodist church in Montgomery, Alabama. He was the first president of the Montgomery Korean-American Association and remained active in it throughout his life.

Since his early teens Dr. Kim had been separated from his father, mother, and their other children in North Korea. It was forbidden for many years for Americans to travel to North Korea, and relations between the two countries were about as bad as relations can be short of a hot war. Finally when limited travel was permitted he did return in 1981 for an emotional reunion with his mother and siblings. He was able to give his mother a little financial help, and bring his own family to North Korea in a later visit.

In his younger days in America, before I met him, Dr. Kim was a body-builder for a while, and distinguished himself in this as in his other endeavors. In the 1990's he had an operation for a hematoma, but continued successfully with his teaching and research afterwards. In his last years he had a number of health problems, including heart problems requiring a quadruple bypass operation and kidney failure requiring dialysis.

Personally, Dr. Kim was cheerful and friendly and could be quite witty on occasion. In many respects he was rather easy-going and unpretentious. Dr. Kim was glad to talk with ordinary people like the custodians of our building as well as with famous mathematicians, and he always remembered the custodians generously at Christmas. 